\title{
Detection and analysis of tick-borne infections in communal dogs of northwest Zimbabwe
}

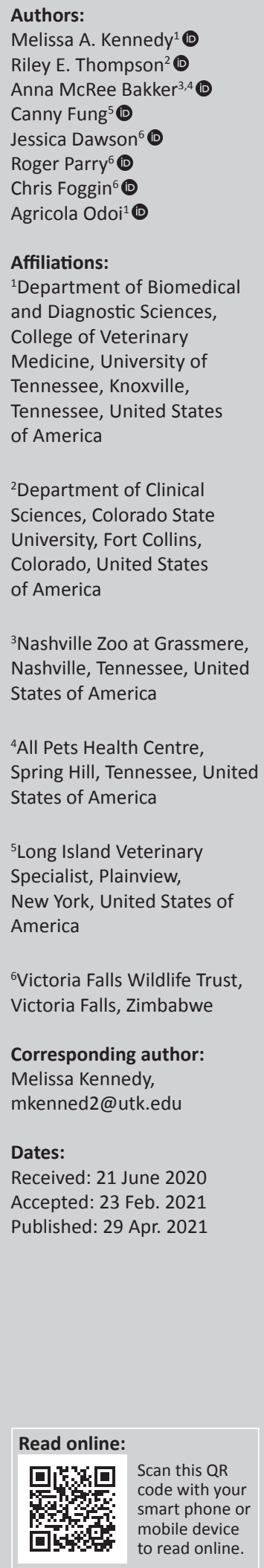

Domestic dogs (Canis familiaris) may serve as a reservoir or a sentinel for infectious disease pathogens that can affect human and wildlife health. To understand the role of tick-borne diseases in rural and lesser developed regions, we investigated the prevalence of several tickborne pathogens in communal dogs of Zimbabwe. Blood samples from $225 \mathrm{dogs}$ in northwest Zimbabwe were assessed by serology for Ehrlichia canis, Anaplasma phagocytophilum and Borrelia burgdorferi, and 241 samples were assessed by polymerase chain reaction (PCR) for Ehrlichia. There was a high seroprevalence (73\%) of E. canis-specific antibodies in domestic dogs in northwest Zimbabwe, but follow up analyses via PCR and genetic sequencing indicated only $7.5 \%$ of the canines were actively infected with the organism. Whilst indicating that an organism serologically related to E. canis is likely present in the region, this data also shows that the organism is currently present in a relative minority of the domestic dogs in the region. Its presence as evidenced by both serologic and PCR analysis is significant because of the 'one health' paradigm, where humans and wildlife may be affected by the exposure to this pathogen in domestic dogs.

Keywords: canine; tick; Southern Africa; Ehrlichia; one health.

\section{Introduction}

Tick-borne diseases pose a significant risk to humans and domestic animals as well as wildlife in sub-Saharan Africa (Dantas-Torres, Chomel \& Otranto 2012; Lightfoot \& Norval 1981; Perry \& Young 1995). Dogs may be the reservoirs of several infectious agents of significance, including tick-borne pathogens, and can serve as sentinels indicating when specific pathogens may be present in an area (Cleaveland et al. 2006; Day 2011; McRee et al. 2014). These agents directly impact the health and welfare of domestic dogs and may also have significant effects on wildlife and humans as well as other domestic species with which they interact (Cleaveland et al. 2006). Specifically, the 'One Health' paradigm, which recognises the interconnectivity of humans, animals and the environment, has been used to demonstrate that domestic dogs and cats are involved in transmission cycles of some tick-borne diseases (Skotarczak 2018). Likewise, endangered African wild dogs (Lycaon pictus) show increased pathogen exposure when in contact with domestic dogs (Woodroffe et al. 2012).

Ticks bites can transmit the bacterial pathogens Ehrlichia spp., Anaplasma spp. and Borrelia burdorferi (Groves et al. 1975; Johnson et al. 1984; Stuen 2007). Canine ehrlichiosis is known to occur in South Africa with seroprevalence levels of up to $75 \%$ with a higher prevalence in economically depressed areas, yet the causative organism has neither been isolated nor characterised (Inokuma et al. 2005; Pretorius \& Kelly 1998). There is even less definitive data from other parts of Africa. A serological survey for antibodies reactive with E. canis done on 228 dogs in rural Zimbabwe in 2004 showed evidence of exposure in over a third of the dogs tested (Kelly, Eoghain \& Raoult 2004). Only one of these pathogens, B. burdorferi (Lyme disease), can be prevented by vaccination, and Lyme disease has not yet been isolated in Zimbabwe. Furthermore, many people in rural Zimbabwe lack the financial resources to purchase vaccines for their dogs. Additionally, tick control is important for prevention of these tick-borne bacterial pathogens, although medications available for tick control in dogs are also expensive.

Good quality data on the importance and means of control of infectious diseases in sub-Saharan Africa are deficient partly because of lack of access to veterinary attention as well as economic

How to cite this article: Kennedy, M.A., Thompson, R.E., McRee Bakker, A., Fung, C., Dawson, J., Parry, R. et al., 2021, 'Detection and analysis of tick-borne infections in communal dogs of northwest Zimbabwe', Journal of the South African Veterinary Association 92(0), a2096. https://doi.org/10.4102/jsava.v92i0.2096

Copyright: ㄷ 2021. The Authors. Licensee: AOSIS. This work is licensed under the Creative Commons Attribution License. 
barriers (McDermott \& Arimi 2002). Since many infectious pathogens affect multiple hosts, it is often more feasible, less expensive and less risky to determine the prevalence of various infectious agents in a domestic species - one that shares an environment with human and wildlife populations. Our objective was to investigate the seroprevalence of three bacterial agents carried by ticks (Ehrlichia canis, Anaplasma phagocytophilum and Borrelia burgdorferi). In addition, detection of the most seroprevalent infectious agent related to E. canis was undertaken using PCR on whole blood.

\section{Research methods and design Sites}

Dogs inhabiting the Hwange District Rural communal lands bordering both the Victoria Falls and the Zambezi National Park were used for this investigation. These lands are in the vicinity of wildlife preserves and encompass a major township in Zimbabwe. The annual rainfall in the Hwange District is less than $450 \mathrm{~mm}$ annually, and the temperatures are as high as $25^{\circ} \mathrm{C}$ and above (Nhemachena et al. 2014). Sampling was performed during periodic cattle dipping at 13 established sites: six in 2012 (Breakfast, Chidobe, Chizuma, Donrovan, Kachechete and Woodland) and seven in 2014 (Chidobe, Chinotimba, Lupinyu, Mflandawonye, Monde, Mosi-Oa-Tunya and Mvuti). Chidobe was the only site visited both years.

\section{Sampling}

Dogs were aged based on appearance, dentition and history when known. Dogs were classified as adults ( $>3$ years old), young adults (1-3 years old) and juvenile ( $<1$ year). Dog owners were encouraged to participate in the study by providing donated multivalent canine distemper-canine adenovirus-2-canine parvovirus-2 and rabies vaccines (Merial, Atlanta, GA, United States [US]) as incentives.

\section{Enzyme-linked immunosorbent assay}

Serum samples $(n=225)$ collected in 2012 were tested for antibodies to E. canis, A. phagocytophilum, B. burgdorferi and Dirofilaria immitis using the IDEXX 4DX SNAP enzymelinked immunosorbent assay (ELISA) (IDEXX, Inc., Portland, ME, US) following manufacturer instructions. Borrelia burgdorferi was primarily investigated because of its inclusion in the ELISA kit; however, evaluating potential spread of Lyme disease was a secondary benefit. Serologic testing on samples collected in 2014 was not done, as kits were unavailable.

\section{Polymerase chain reaction (PCR) and genetic analysis}

To detect Ehrlichia organisms, we first extracted whole blood using the QIAamp deoxyribonucleic acid (DNA) Blood Mini Kit (Qiagen, Valencia, CA, US) in Zimbabwe. Extracted DNA was then transported at room temperature to the University of Tennessee College of Veterinary Medicine laboratory and stored at $-80{ }^{\circ} \mathrm{C}$ until amplification of an $\sim 345$ base pair (bp) fragment of the $16 \mathrm{~S}$ recombinant DNA (rDNA) of Ehrlichia (Branger, Rolain \& Raoult 2004). A total of 241 canine blood samples were screened for Ehrlichia with this method (120 from 2012 and 121 from 2014). Rather than incorporating SYBR green (a Synergy Brand Inc. nucleic acid dye used in quantitative PCR) into the reaction mixture, PCR was performed with conventional methods and amplified products were visualised by agarose gel electrophoresis and gel staining. Amplified products were purified using the QIAquick Gel Extraction Kit (Qiagen, Valencia, CA, US) per manufacturer instructions and genetically sequenced at the Molecular Biology Facilities of the University of Tennessee (Knoxville, TN, US). Resulting sequences were analysed using Lasergene 9 (DNASTAR, Inc., Madison, WI, US) and compared to known sequences in GenBank (Basic Local Alignment Search Tool [BLAST], National Center for Biotechnology Information [NCBI]).

\section{Data analysis}

Serological and PCR results were classified and recorded as positive or negative for each pathogen tested. Crude and factor-specific seroprevalence of each pathogen was then computed. Factors considered were animal age, sex and geographic location. Associations between seroprevalence and each of the factors were assessed using Fisher's exact test. A $p$-value of $<0.05$ was used to indicate statistical significance.

\section{Results Demographic data}

Dogs tested in 2012 were primarily (84\%) young adults. There were more males (68\%) than females (32\%), and more samples were tested in July (71\%) than in June (29\%) 2012. In $2014,90 \%$ of the samples were collected from young adult dogs, and all samples were collected in mid-July.

\section{Serologic data}

Based on serologic testing $10 \%, 0 \%, 1 \%$ and $73 \%$ of the dogs had been exposed to Anaplasma, Borrelia, Dirofilaria and Ehrlichia, respectively. There was no association between seroprevalence of Ehrlichia with either age $(p=0.4435)$ or sex $(p=0.0945)$. However, there was a significant $(p=0.0029)$ association between location and seroprevalence of Ehrlichia, with Chisuma having the highest seroprevalence $(86.7 \%$; $39 / 45)$, followed by Woodland $(76.9 \% ; 30 / 39)$, Breakfast (75.9\%; 22/29), Donrovan (71.1\%; 27/38), Kachechete $(70.3 \% ; 26 / 37)$ and Chidobe $(35 \% ; 7 / 20)$. Also, there was a significantly ( $p=0.0051$ ) higher seroprevalence of Ehrlichia in July $(78 \% ; 118 / 151)$ than in June $(57 \% ; 33 / 57)$.

\section{Polymerase chain reaction data}

A total of 241 (120 from 2012 and 121 from 2014) samples were tested for Ehrlichia using PCR. The overall prevalence of Ehrlichia based on the PCR results was $7.5 \%(18 / 241)$, all of which were most homologous by genetic sequencing to E. canis. Thus, this organism was determined to be an E. canis-like organism. There was a significant $(p=0.044)$ association between the organisms' prevalence based on 
PCR test and year with 2012 having a lower prevalence $(4.17 \% ; 5 / 120)$ than $2014(10.74 \% ; 13 / 121)$. There were no significant $(p=0.592)$ sex differences in the prevalence of Ehrlichial canis-related organism during 2014 based on PCR results. However, there was a significant $(p<0.001)$ association between location and its prevalence based on PCR results in 2014 with Lupinyu having the highest prevalence $(80 \% ; 4 / 5)$, followed by Mvuti $(24 \% ; 6 / 25)$, Mosi-Oa-Tunya $(5.41 \% ; 2 / 37)$ and Chidobe $(4 \% ; 1 / 25)$. The remaining three locations had no positive samples.

\section{Discussion}

This investigation shows a significant level of exposure to an E. canis-related organism amongst communal dogs in Zimbabwe. For those whom serologic assays alone were done, it is unknown when exposure occurred. Genetic detection of the organism revealed a much lower prevalence level for active current infection. Testing was done opportunistically during June and July of 2012 and 2014. This corresponds to winter, or the dry season in Zimbabwe, when tick populations are not expected to be at their highest. Nevertheless, the organism was detected and found to be closely related to E. canis. The majority of dogs tested were young adults; even so, there was not an age association with exposure. That is, exposure likely occurs very early in a dog's life, as soon as the first tick season after birth. There was not an even distribution of exposed dogs in the region tested, but exposure was found at a considerable level in all areas.

Because there is extensive serologic cross reactivity amongst ehrlichial species, we cannot say for certain that other species of ehrlichial organisms such as E. chaffeensis and E. ruminantium or even uncharacterised organisms are not present (Kelly et al. 2004). Whilst all PCR-positive results here identified infections because of E. canis, it is possible that other ehrlichial organisms may be present in dog populations. It is unclear as to which tick species is associated with these pathogens. Further studies of ticks involved are needed in order to determine vector associations.

Many tick-borne diseases are endemic in Africa, including organisms related to Ehrlichia canis and Anaplasma phagocytophilum. A growing number of new Ehrlichia organisms are being recognised (Allsopp \& Allsopp 2001) that may affect dogs. Unfortunately, in Zimbabwe, Ehrlichia and Anaplasma have not yet been directly isolated from tick species to determine the vector; however, a recent survey in South Africa determined that E. canis was identified in Rhipicephalus sanguineus ticks, and that both Rhipicephalus sanguineus and Haemaphysalis elliptica species carry A. phagocytophilum, but not the Amblyomma ticks (Mtshali et al. 2017). Related organisms that infect humans are also carried by these vectors and occur in Africa, including E. chaffeensis and E. ewingii (Brouqui et al. 1994; Ndip et al. 2005). In 2000, an organism related to A. phagocytophilum, the agent of human and canine granulocytic anaplasmosis was identified in dogs in South Africa (Inokuma et al. 2005). The significance of all these infectious agents amongst animals in Zimbabwe remains unknown. There is a critical need to determine the prevalence of both Ehrlichia and Anaplasma in the domesticated canine population to identify the potential vectors associated with those canines and to characterise the risk factors associated with each pathogen. Without this knowledge, it will not be possible to manage these ticks and minimise pathogen transmission of these emerging and preventable diseases.

In summary, testing of communal dogs in Zimbabwe revealed a high seroprevalence for organisms related to E. canis. Polymerase chain reaction detection of the organism indicated that there is significant identity with E. canis, but as only 18 samples produced positive results, it is possible other serologically related organisms may also be involved.

\section{Acknowledgements Competing interests}

The authors declare that they have no financial or personal relationships that may have inappropriately influenced them in writing this article.

\section{Authors' contributions}

A.M.B. collected samples, performed ELISA testing, and extracted deoxyribonucleic acid (DNA) for samples in 2012. R.E.T collected and extracted DNA from samples in 2014 and assisted with manuscript preparation. C.F. performed PCR analysis. J.D., R.P., and C.F. assisted with sample collection and arranged local logistics. A.O. performed the statistical analysis and assisted with manuscript preparation. M.A.K was the project leader and was responsible for experimental design and analysis of data.

\section{Ethical considerations}

Research was approved by the University of Tennessee Animal Care and Use Committee. The Wild Horizons Wildlife Trust invited the authors to assist with disease surveillance and diagnosis at the Wildlife Laboratory and Clinic in Zimbabwe. The facility is the only one in the Kavanago Zambezi Trans-frontier Conservation Area (KAZA TFCA).

All samples were collected under the direct supervision of staff including a veterinarian from Victoria Falls Wildlife Trust in accordance with their mission, which states: 'To actively advance and promote environmental conservation and the sustainable use of indigenous resources in Southern Africa'.

\section{Funding information}

A.M. and R.E.T. were funded for travel by Morris Animal Foundation Veterinary Fellow Scholarship.

\section{Data availability}

The authors confirm that the data supporting the findings of this study are available within the article. 


\section{Disclaimer}

The views and opinions expressed in this article are those of the authors and do not necessarily reflect the official policy or position of any affiliated agency of the authors.

\section{References}

Allsopp, M.T.E.P. \& Allsopp, B.A., 2001, 'Novel Ehrlichia genotype detected in dogs in South Africa', Journal of Clinical Microbiology 39(11), 4204-4207. https://doi. org/10.1128/JCM.39.11.4204-4207.2001

Branger, S., Rolain, J.M. \& Raoult, D., 2004, 'Evaluation of antibiotic susceptibilities of Ehrlichia canis, Ehrlichia chaffeensis, and Anaplasma phagocytophilum by realtime PCR', Antimicrobial Agents and Chemotherapy 48(12), 4822-4828. https:// doi.org/10.1128/AAC.48.12.4822-4828.2004

Brouqui, P., Le Cam, C., Kelly, P.J., Laurens, R., Tounkara, A., Sawadogo, S. et al., 1994, 'Serologic evidence for human ehrlichiosis in Africa', European Journal of Epidemiology 10(6), 695-698. https://doi.org/10.1007/BF01719283

Cleaveland, S., Kaare, M., Knobel, D. \& Laurenson, M.K., 2006, 'Canine vaccination Providing broader benefits for disease control', Veterinary Microbiology 117(1), 43-50. https://doi.org/10.1016/j.vetmic.2006.04.009

Dantas-Torres, F., Chomel, B.B. \& Otranto, D., 2012, 'Ticks and tick-borne diseases: A one health perspective', Trends in Parasitology 28(10), 437-446. https://doi. org/10.1016/j.pt.2012.07.003

Day, M.J., 2011, 'The immunopathology of canine vector-borne diseases', Parasites \& Vectors 4, 48. https://doi.org/10.1186/1756-3305-4-48

Groves, M.G., Dennis, G.L., Amyx, H.L. \& Huxsoll, D.L., 1975, 'Transmission of Ehrlichia canis to dogs by ticks (Rhipicephalus sanguineus)', American Journal of Veterinary Research 36(7), 937-940.

Inokuma, H., Oyamada, M., Kelly, P.J., Jacobson, L.A., Fournier, P.E., Itamoto, K. et al., 2005, 'Molecular detection of a new Anaplasma species closely related to Anaplasma phagocytophilum in canine blood from South Africa', Journal of Clinical Microbiology 43(6), 2934-2937. https://doi.org/10.1128/JCM.43.6.29342937.2005

Johnson, R.C., Schmid, G.P., Hyde, F.W., Steigerwalt, A.G. \& Brenner, D.J., 1984 'Borrelia burgdorferi sp. nov.: Etiologic agent of Lyme disease', International Journal of Systematic and Evolutionary Microbiology 34(4), 496-497. https://doi. org/10.1099/00207713-34-4-496

Kelly, P.J., Eoghain, G.N. \& Raoult, D., 2004, 'Antibodies reactive with Bartonella henselae and Ehrlichia canis in dogs from the communal lands of Zimbabwe', Journal of the South African Veterinary Association 75(3), 116-120. https://doi. org/10.4102/jsava.v75i3.465
Lightfoot, C.J. \& Norval, R.A.I., 1981, 'Tick problems in wildlife in Zimbabwe. 1: The effects of tick parasitism on wild ungulates', South African Journal of Wildlife Research-24-Month Delayed Open Access 11(2), 41-45.

McDermott, J.J. \& Arimi, S.M., 2002, 'Brucellosis in sub-Saharan Africa: Epidemiology, control and impact', Veterinary Microbiology 90(1-4), 111-134. https://doi. org/10.1016/S0378-1135(02)00249-3

McRee, A., Wilkes, R.P., Dawson, J., Parry, R., Foggin, C., Adams, H. et al., 2014 'Serological detection of infection with canine distemper virus, canine parvovirus and canine adenovirus in communal dogs from Zimbabwe', Journal of the South African Veterinary Association 85(1), a1110, 2. https://doi.org/10.4102/jsava. v85i1.1110

Mtshali, K., Nakao, R., Sugimoto, C. \& Thekisoe, O., 2017, 'Occurrence of Coxiella burnetiid, Ehrlichia canis, Rickettsia species and Anaplasma phagocytophilum-like bacterium in ticks collected from dogs and cats in South Africa', Journal of the South African Veterinary Association 88(0), a1390. https://doi.org/10.4102/jsava. v88i0.1390

Ndip, L.M., Ndip, R.N., Esemu, S.N., Dickmu, V.L., Fokam, E.B., Walker, D.H. et al., 2005, 'Ehrlichial infection in Cameroonian canines by Ehrlichia canis and Ehrlichia ewingii', Veterinary Microbiology 111(1-2), 59-66. https://doi.org/10.1016/j. vetmic.2005.08.010

Nhemachena, C., Mano, R., Mudombi, S. \& Muwanigwa, V., 2014, 'Climate change adaptation for rural communities dependent on agriculture and tourism in marginal farming areas of the Hwange District, Zimbabwe', African Journal of Agricultural Research 9(26), 2045-2054. https://doi.org/10.5897/ AJAR2013.6779

Perry, B.D. \& Young, A.S., 1995, 'The past and future roles of epidemiology and economics in the control of tick-borne diseases of livestock in Africa: The case of theileriosis', Preventive Veterinary Medicine 25(2), 107-120. https://doi.org/ 10.1016/0167-5877(95)00546-3

Pretorius, A.M. \& Kelly P.J., 1998, 'Serological survey for antibodies reactive with Ehrlichia canis and $E$. chaffeensis in dogs from the Bloemfontein area, South Africa', Journal of the South African Veterinary Association 69(4), 126-128. https://doi.org/10.4102/jsava.v69i4.840

Skotarczak, B., 2018, 'The role of companion animals in the environmental circulation of tick-borne bacterial pathogens', Annals of Agricultural and Environmental Medicine 25(3), 473-480. https://doi.org/10.26444/ aaem/93381

Stuen, S., 2007, 'Anaplasma phagocytophilum - The most widespread tick-borne infection in animals in Europe', Veterinary Research Communications 31(1), 79-84. https://doi.org/10.1007/s11259-007-0071-y

Woodroffe, R., Prager, K.C., Munson, L., Conrad, P.A., Dubovi, E.J. \& Mazet, J.A., 2012, 'Contact with domestic dogs increases pathogen exposure in endangered African wild dogs (Lycaon pictus)', PLoS One 7(1), e30099. https://doi.org/10.1371/ journal.pone.0030099 